\title{
Methicillin Susceptible Staphylococcus
}

\section{Aureus}

National Cancer Institute

\section{Source}

National Cancer Institute. Methicillin Susceptible Staphylococcus Aureus. NCI Thesaurus.

Code C123516.

A species of Gram-positive coccus-shaped bacterium in the family Micrococcaceae. This strain of S. aureus retains its native sensitivity to methicillin and other beta-lactam antibiotics. 